\title{
Characterization of the spatial structure of the canopy in Pinus silvestris L. stands in Central Spain from hemispherical photographs
}

\author{
Fernando Montes , Agustín Rubio , Ignacio Barbeito , Isabel Cañellas \\ Departamento de Silvopascicultura, Universidad Politécnica de Madrid, ETSI de Montes, Ciudad Universitaria, s/n. 28040 Madrid, Spain \\ CIFOR-INIA, Ctra. La Coruña, km 7.5, Madrid, Spain
}

Received 9 January 2007; received in revised form 4 July 2007 ; accepted 6 September 2007

\begin{abstract}
The spatial pattern was characterized in five experimental plots of 0.5 ha established in Scots pine stands located in the Central Mountain Range of Spain with different ecological conditions and in which different silvicultural practises are employed. A new method is proposed to asses the spatial pattern from hemispherical photographs, based on the variance between the gap fractions in sky sectors, which was calculated as a function of the angular distance. The results were compared with the spatial pattern analysis based on the second moment measure, and with the analysis of the structure of the tree number semivariogram. The three methods give a very similar scale of the pattern for most of the plots. The mature plot with more intensive silviculture showed a regular pattern at scales below $6 \mathrm{~m}$. The mature plot in which the silviculture was less intensive showed a cluster pattern at scales around $10 \mathrm{~m}$, and clustering at similar scales was detected during regeneration. Cluster patterns at scales around $5 \mathrm{~m}$ were found at the upper limit of the altitudinal range of Scots pine as well as at the lower limit, where Pyrenean oak stands merge with the pinewood. The method proposed allows the scale of the pattern of the canopy to be determined from hemispherical photographs, and can be easily implemented in forest inventories.
\end{abstract}

Keywords: Ripley $L(d)$ function; Henispherical photograph; Spatial pattern; Gap fraction; Clumping; Angular semivariance

\section{Introduction}

The fact that the major part of all wildlife is associated with forests means that the conservation of biodiversity in forest ecosystems must be one of the main objectives of sustainable forestry (Hunter, 1990). Biodiversity comprises three key aspects: species composition, structure and function (Magurran, 1988). Forest management brings about structural changes in forest ecosystems (Franklin et al., 2002; Montes et al., 2005) which may change the availability of certain structural features and microhabitat conditions. An adequate assessment of the structure and the structural changes is indispensable if biodiversity is to be included in forest management objectives.

Perhaps, one of the most relevant aspects of forest structure is the spatial pattern of the trees. The analysis of the spatial pattern of forest stands can provide valuable information on the underlying processes, such as intraspecific or interspecific competition or facilitation or the response of vegetation to environmental heterogeneity (e.g., Amarasekare and Nisbet, 2001; Keitt et al., 2002; Nicotra et al., 1999), and also avoids the possible misinterpretation of statistical analyses in the presence of spatial structure (Legendre and Legendre, 1998; Legendre et al., 2004). Moreover, the spatial pattern of managed stands is mainly determined by the silviculture applied, so understanding factors such as the spatial interaction among different species, the scale at which the processes underlying tree development operate or the effect of site conditions on the distribution of species might have implications for forest management (Maestre et al., 2005). However, the causal factor cannot be directly inferred from the spatial structure because different processes might result in similar pattems. Spatial pattern analysis is normally used in forest science to identify pattern from empirical data, but the development of spatially explicit models to test the underlying theoretical processes is still limited. In addition, there are a wide variety of spatial analysis techniques, and not all of them are suitable for analysing certain spatial data or determining certain spatial properties (Perry et al., 2002; Dale et al., 2002). 
Watt (1947), who pioneered the study of vegetation patterns. considered the landscape in terms of a mosaic of patches in different successional stages. The spatial pattern can be analysed at nearest neighbour distances for individual trees using the Cox index or the Clark and Evans index (Neuman and Starlinger. 2001). At broader scales, possible analysis techniques include the characterization of second moment properties of the pattern (where mapped data are available at stand level) through Ripley's $K(d)$ function (Moeur. 1993; Aldrich et al., 2003; Montes et al., 2004) or the analysis of the variance between quadrats in nested scales (Dale, 1999: Hanewinkel, 2004). Geostatistical tools may also be used at broader scales or where data are taken at sample points (Kuuluvainen et al., 1996). These methods require special sampling strategies or mapped data and are usually restricted to experimental plots due to the high cost which such methods would involve in forest surveys. This problem can be partly resolved by using remote sensing devices to analyse the spatial pattern of the forest (Koukoulas and Blackburn. 2005). Hemispherical photographs have been used to assess some features of forest canopies. mainly in leaf area index estimation and under-canopy radiation modelling. There are several approaches used for estimating the clumping coefficient $\Omega_{0}$ which take into account the clustering effect on light transmittance derived from the Beer-Lambert law (Nilson. 1971), through gap distribution analysed in hemispherical photographs (Kucharik et al., 1999: Chen and Cihlar. 1995; Fassnacht et al., 1994: Neumann et al., 1989). These approaches quantify the increase in the gap fraction when the foliage displays a clumped distribution, but do not provide a spatial scale for the pattern.

In this paper, the spatial pattern of Scots pine (Pinus sylvestris $\mathbf{L}$.) stands in the Central Mountain Range of Spain is assessed using hemispherical photographs. The pattern is defined in the presented approach by the distribution of the foliage in the canopy layer and may therefore be related to the light conditions within the stand. The light conditions, which are associated with many ecological processes, are closely linked to forest structure (Druckenbrod et al.. 2005; Montgomery and Chazdon, 2001; Denslow and Guzman, 2000) and determine the suitability of the site for the regeneration and development of most plant species (DeLagrange et al., 2004; Montgomery and Chazdon. 2002: Nicotra et al., 1999). In fact, the pattern of regeneration in Scots pine forests seems to be related to the spatial arrangement of the light conditions (Pardos et al., 2007) as well as to the spatial distribution of the remaining mother trees (Montes and Cañellas, 2007).

The proposed technique for assessing the spatial pattern is based on the variance between the gap fractions in sky sectors, which is calculated as a finction of the angular distance, as with variogram estimation in geostatistics. The method used to calculate the angular semivariogram was also developed in the framework of this research. The results are compared with the spatial pattern analysis based on the Ripley $K(d)$ function (Ripley. 1977) and also with the analysis of the tree number by quadrat semivariogram.

\section{Material and methods}

Two Scots pine forests located in the Central Mountain Range of Spain composed the study area. In Novafria forest. the regeneration fellings are carried out over a 20-year period when the stand reaches 100 years. An intensive thinning and pruning regime is applied throughout the life of the stand. In Valsain, the regeneration fellings are carried out over a 40-year period when the stand reaches 120 years. so that the newly established recruitment coexists with the remaining mother trees during the first developmental stages. A moderate thinning regime is applied. leaving higher densities than in the stands at Navafria.

In these forests. five 0.5 ha plots were established at the following locations:

(i) A mature stand at Navafria in which regeneration fellings were in progress (NM).

(ii) A mature stand at Valsain in which regeneration fellings had just begun (VM).

(iii) A stand at Valsain in which the regeneration period was ending (VR), where the mother trees coexist with young trees of diameter at breast height ( $\mathrm{DBH}$ ) between 10 and 25 and saplings higher than $1.30 \mathrm{~m}$ and with DBH smaller than $10 \mathrm{~cm}$.

(iv) In Valsain forest at an altitude of $1800 \mathrm{~m}$, which is the upper altitudinal limit for Scots pine (V1800).

(v) In Valsain forest at an altitude of $1200 \mathrm{~m}$, where Pyrenean oak (Quercus pyrenaica Willd.) stands merge with the pine wood (V1200).

All the trees higher than $1.30 \mathrm{~m}$ were positioned in a $2 \mathrm{~m} \times 2 \mathrm{~m}$ grid marked on the terrain in the 0.5 ha plot and also through their $X Y$ coordinates if their DBH was larger than $10 \mathrm{~cm}$. The $\mathrm{DBH}$, height and crown height of each tree were measured. The crowns were assimilated to ellipsoids. considering the widest cross-section to be located at the mid point of the crown. The characterization of the stands within each plot is shown in Table 1. In each plot, ten hemispherical photographs were taken on a systematic grid using a Nikon Coolpix 4500 with a Nikon ${ }^{\mathrm{B}}$ FC-E8 fisheye lens, fixing the

Table 1

Stand level variables in the experimental plots in Navafría forest (NM) and Valsain forest (VM, VR. V1200 and V1800)

\begin{tabular}{llclllr}
\hline Plot & $\begin{array}{l}\text { N DBH } \geq \\
10 \mathrm{~cm}\end{array}$ & $\begin{array}{l}\text { N DBH } \\
10 \mathrm{~cm}\end{array}$ & BA & DBH & HT & HMC \\
\hline NM & 108 & 0 & 16.8 & $44.1(6.1)$ & $21.88(1.96)$ & 18.82 \\
VM & 318 & 518 & 41.2 & $39.7(8.29)$ & $24.52(10.84)$ & 20.91 \\
VR & 480 & 2734 & 28.48 & $19.7(12.1)$ & $16.11(5.64)$ & 12.23 \\
V1200 & 608 & 964 & 25.2 & $18.8(13.0)$ & $16.79(5.18)$ & 10.39 \\
V1800 & 578 & 244 & 22.7 & $19.9(9.9)$ & $12.18(4.19)$ & 8.02 \\
\hline
\end{tabular}

$N$ DBH $\geq 10 \mathrm{~cm}$. number of trees with DBH larger than $10 \mathrm{~cm} / \mathrm{ha} ; N$ DBH $<10 \mathrm{~cm}$, number of trees with DBH smaller than $10 \mathrm{~cm} / \mathrm{ha}$; BA, basal area $\left(\mathrm{m}^{2} / \mathrm{ha}\right) ; \mathrm{DBH}$, mean diameter at breast hejght of trees with $\mathrm{DBH} \geq 10 \mathrm{~cm}$ (cm) and standard error (in brackets): HT, weighted by tree basal area mean total height accounting for all the trees in the plot $(\mathrm{m})$ and height standard error (in brackets) and HMC. weighted by tree basal area mid crown height (m). 
optical axis to the zenith direction. To obtain the gap fraction from the hemispherical photographs, the Hemiview 2.1 Canopy Analysis Software (Delta-T Devices Ltd.) was used.

\subsection{Spatial pattern analysis from the hemispherical photographs}

In this study, a method for characterising the spatial pattern of the crowns from hemispherical photography has been developed based on the calculation of an angular semivariance of the gap fraction. The gap fraction was derived from the photograph by dividing the sky map into 16 angular sectors (corresponding to azimuth angles of $22.5^{\circ}$ ) and nine angular rings (corresponding to zenith angles of $10^{\circ}$ ) (Fig. 1). This angular semivariance is calculated as a function of the azimuth angle between the central point of the sky sectors and is calculated for each ring of zenith angle $\theta$ through the following equation:

$\hat{\gamma}(\delta)_{\theta}=\frac{1}{2 N(\delta)} \sum_{a=1}^{N(\delta)}\left[z\left(u_{a}\right)-z\left(u_{a}+\delta\right)\right]^{2}$

where $\delta$ is the angle between the meridians through the sectors $u_{a}$ and $u_{a}+a, z\left(u_{a}\right)$ and $z\left(u_{a}+a\right)$ are the values of the variable, i.e. the gap fraction, in sectors $u_{a}$ and $u_{a}+a$, calculating Eq. (1) for each zenith angle $\theta$. The semivariance value for each angular distance was averaged for the 10 photographs within each 0.5 ha plot. The spherical variogram model (Eq. (2)) was fitted to the angular variogram using the least squares procedure to obtain the sill $(c)$ and angular range $(\alpha)$ of the spherical model, whereas the nugget $\left(c_{0}\right)$ was set to 0 considering the continuous nature of the variable gap fraction

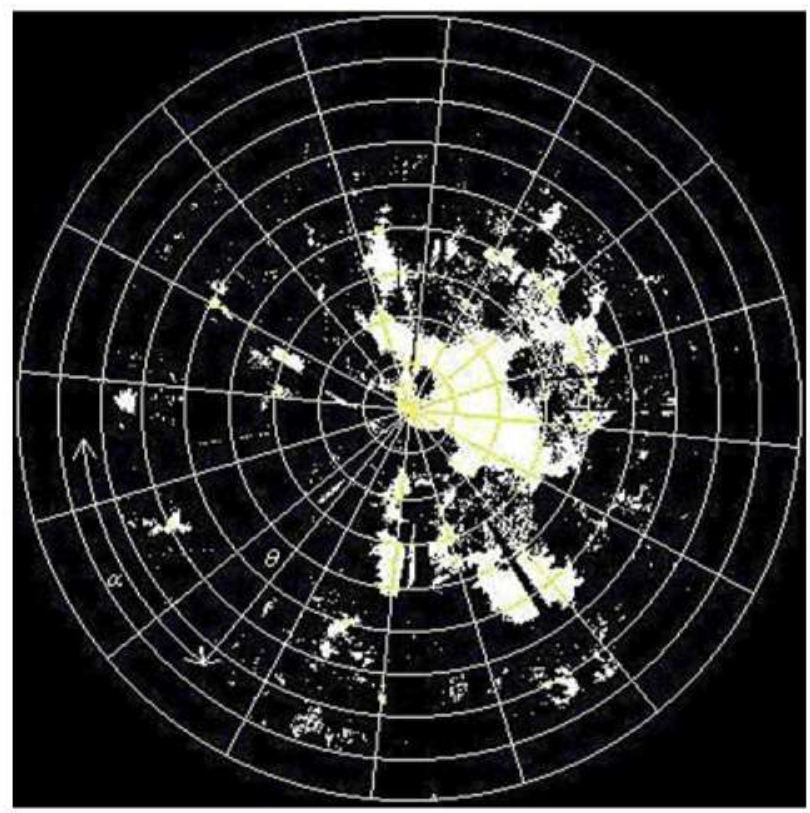

Fig. 1. Division of the sky map into sectors comprising an azimuth angle of $22.5^{\circ}$ and rings comprising a zenith angle of $10^{\circ}$ (analysis carried out with Hemiview 2.1, Canopy Analysis Software (Delta-T Devices Ltd.) software). and the continuity of the sky sectors.

$\gamma= \begin{cases}c_{0}+c\left(\frac{3 \delta}{2 \alpha}-\frac{\delta^{3}}{2 \alpha^{3}}\right) & \text { if } \delta \leq \alpha \\ 0 & \text { if } \delta=0 \\ c_{0}+c & \text { if } \delta>\alpha\end{cases}$

The spatial pattern of the canopy was derived from the angular range $(\alpha)$ and the difference between the weighted height to the mid point of the crown (HMC), which is approximately the height corresponding to the maximum crown width for Scots pine in the analysed stands, and the height of the camera lens (hl) (Fig. 2) through Eq. (3).

$d=\sqrt{2}(\mathrm{HMC}-\mathrm{hl}) \tan \theta \sqrt{1-\cos \alpha}$

\subsection{Spatial pattern analysis from the mapped data}

\subsubsection{Spatial pattern of stems: Ripley's $K(d)$ function}

The spatial pattern of the trees with a diameter larger than $10 \mathrm{~cm}$ was analysed using the modification $L(d)$ of Ripley's function $K(d)$ proposed by Besag (Eq. (4)) in the discussion of Ripley's paper (Ripley, 1977) to assess the performance of the proposed technique based on hemispherical photographs. The $L(d)$ transformation linearizes the $K(d)$ function, giving 0 as the expected value under random distribution, and stabilizes its variance:

$L(d)=\sqrt{\frac{\hat{K}(d)}{\pi}}-d$

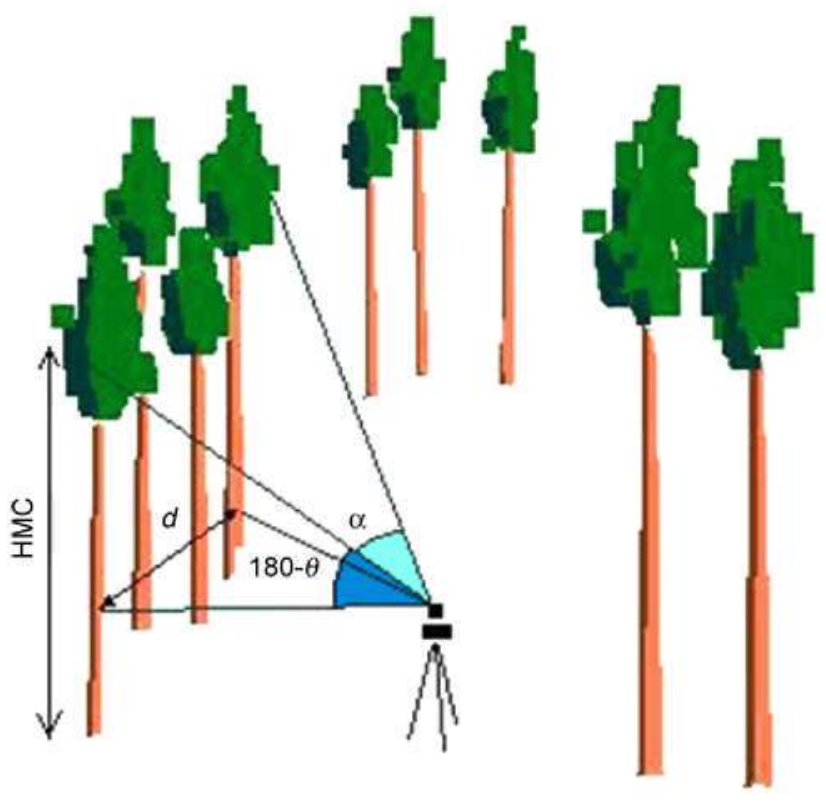

Fig. 2. Variables used to derive the horizontal distance from the angular distance measured at the canopy height in the hemispherical photograph: HMC, weighted height to the middle of the crown of each tree; $\theta$, zenith direction; $\alpha$, angular range; $d$, linear distance. 
$K(d)$ was calculated for each distance $d$ through the equation:

$\lambda K(d)=\sum_{i=1}^{n} \sum_{j=1}^{n} \frac{\delta_{i j}(d)}{n}, i \neq j, \quad \delta_{i j}(d)=\left[\begin{array}{ll}1 & \text { if } d_{i j} \leq d \\ 0 & \text { if } d_{i j}>d\end{array}\right.$

where $\lambda$ is the density of stems per unit area, $d_{i j}$ the distance from tree $i$ to tree $j$, and $n$ the total number of trees in the study region. To deal with the boundary effect of the plot, $\delta_{i j}(d)$ was replaced by $\omega_{\mathrm{ij}}(d)$, which gives zero if stems $i$ and $j$ are more than distance $d$ from each other, or if not, it will give the inverse of the fraction of a circumference centred on $i$ (with the radius being the distance from $i$ to $j$ ) which falls within the plot (Ripley, 1977; Goreaud and Pélissier, 1999).
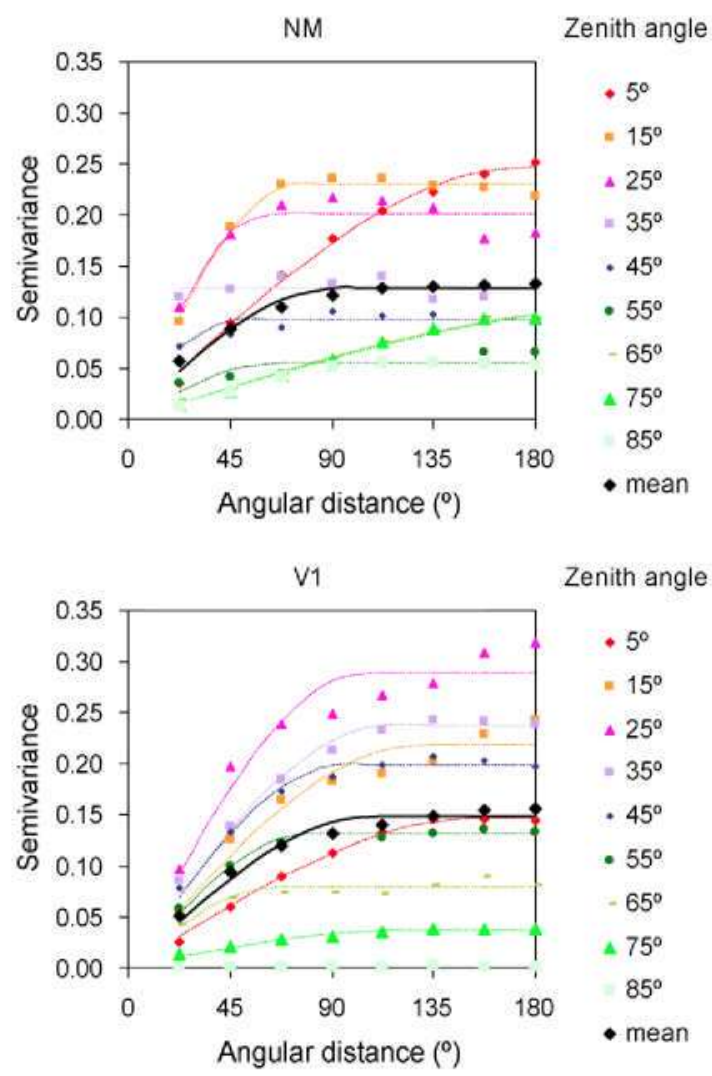

Zenith angle

$$
\begin{aligned}
& \cdot 5^{\circ} \\
& =15^{\circ} \\
& \Delta 25^{\circ} \\
& =35^{\circ} \\
& \text { - } 45^{\circ} \\
& \text { - } 55^{\circ} \\
& -65^{\circ} \\
& 475^{\circ} \\
& 85^{\circ} \\
& \text { - mean }
\end{aligned}
$$

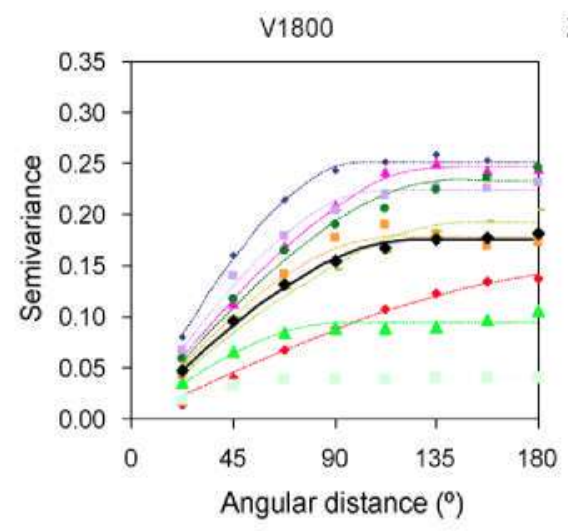

Zenith angle

$$
\begin{aligned}
& .5^{\circ} \\
& =15^{\circ} \\
& +25^{\circ} \\
& =35^{\circ} \\
& .45^{\circ} \\
& -55^{\circ} \\
& -65^{\circ} \\
& -75^{\circ} \\
& 85^{\circ} \\
& - \text { mean }
\end{aligned}
$$

The $L(d)$ function can be used to test a given null hypothesis by selecting an appropriate null model. $L(d)$ is calculated for 99 simulations of the null model; discarding the highest and lowest $5 \%$ of $L(d)$ values for the 99 simulations we can establish the $5 \%$ and 95\% quantiles of the null model (Ripley, 1981). The null models used were those of complete spatial randomness (CSR) and the moving window (MW) estimation of large-scale intensity. The latter incorporates large-scale intensity variation, allowing the null hypothesis to be tested for a heterogeneous Poisson process at small scales. Under the MW model, each point $i$ obtained as a realization of a Poisson distribution, is maintained where a random value generated between 0 and 1 falls below the ratio $\rho_{i} / \rho_{\mathrm{M}}$, where $\rho_{i}$ is the real distribution density in a circle of a given radius centred on point $i$ and $\rho_{\mathrm{M}}$ is the maximum density of
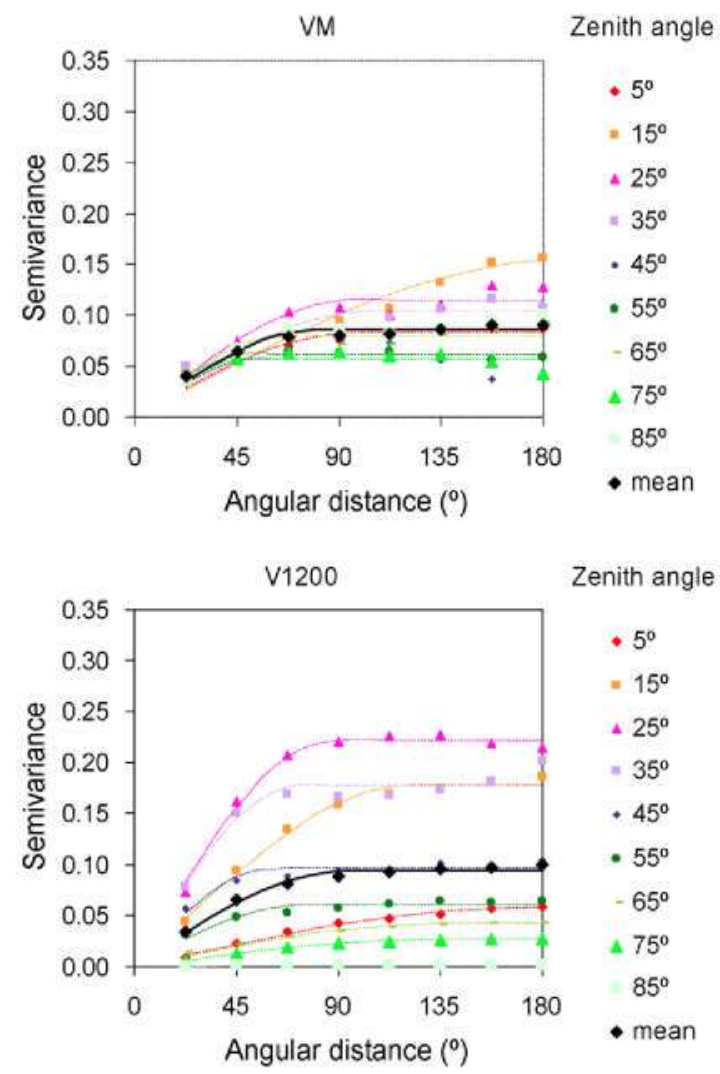

Fig. 3. Empirical angular variograms of the gap fraction for the different zenith angles as well as for the mean of all zenith angles and the spherical model fitted for each zenith angle for the experimental plots NM, mature stand in Navafria; VM, mature stand in Valsain; VR, regenerating stand in Valsain; V1200, at the Scots pine lower altitudinal limit in Valsaín; V1800, at the Scots pine upper altitudinal limit in Valsaín. 
the real distribution of stems in a circle of the same radius centred on any stem within the study area. The total number of points in the study area remains the same as with the real distribution. This null model preserves the observed spatial pattern at scales beyond the chosen radius $r$, enabling possible departures from a heterogeneous Poisson process for scales shorter than $r$ to be checked (Wiegand and Moloney, 2004).

The software used for the calculus of the $L(d)$ function as well as for the null model simulations was developed using Microsoft VisualBasic 6.3 (Copyright ${ }^{\circ}$ 1987-2001 Microsoft Corp).

\subsection{Structural analysis of the semivariogram for the number of trees}

However, the spatial pattern derived from the hemispherical photographs comprises all the trees above the height of the
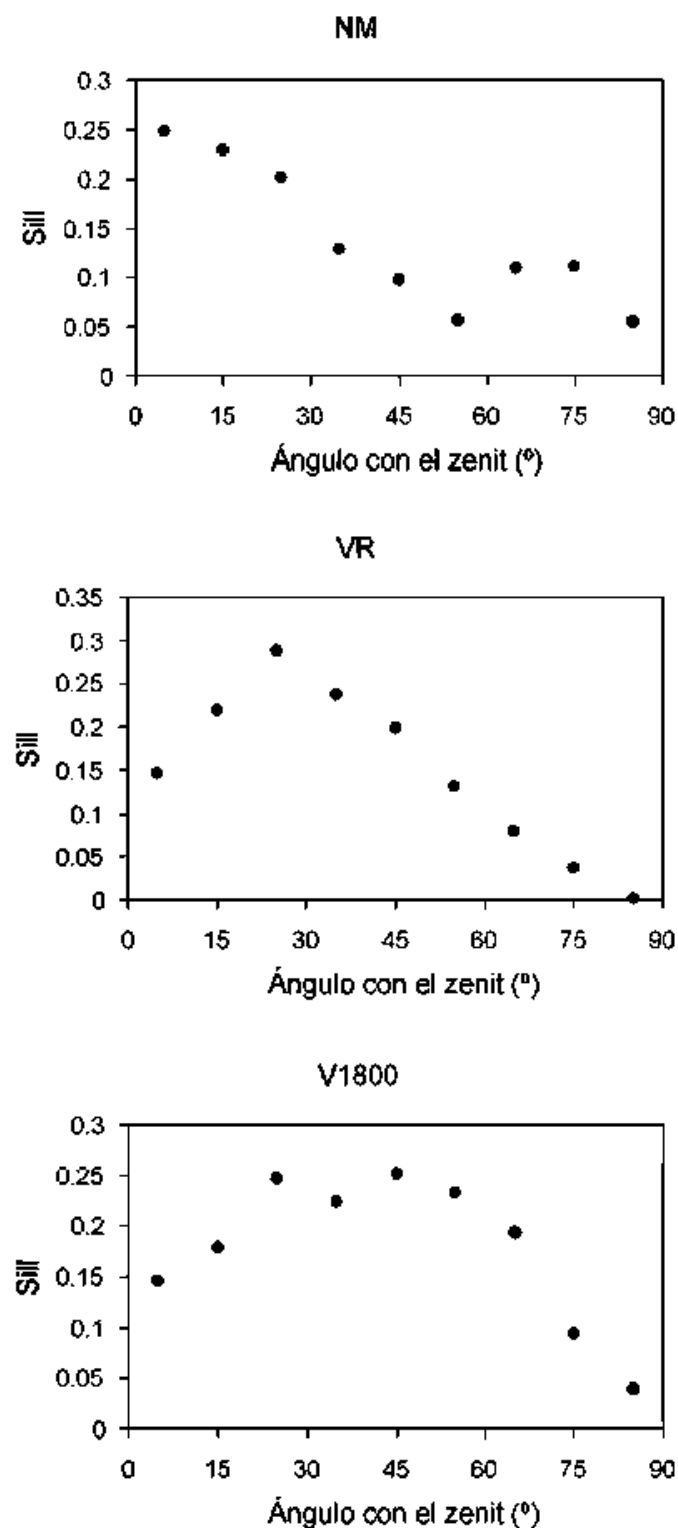

camera lens (i.e.. over $1.30 \mathrm{~m}$ ), whereas the $L(d)$ analyses only accounted for the trees located through their $X Y$ coordinates, i.e. the trees with $\mathrm{DBH} \geq 10 \mathrm{~cm}$. To assess the spatial pattern of all the trees higher than $1.30 \mathrm{~m}$. both with $\mathrm{DBH}<10 \mathrm{~cm}$ and with $\mathrm{DBH} \geq 10 \mathrm{~cm}$, their position in the $2 \mathrm{~m} \times 2 \mathrm{~m}$ grid was used. The empirical semivariogram of the number of trees per quadrat was calculated to determine the range of the spatial autocorrelation:

$\hat{\gamma}(d)=\frac{1}{2 N(d)} \sum_{a=1}^{N(d)}\left[z\left(u_{a}\right)-z\left(u_{a}+d\right)\right]^{2}$

where $N(d)$ is the number of pairs of data at distance $d, z\left(u_{a}\right)$ is the value that the variable $z$ takes at location $u_{a}$, and $\mathrm{z}\left(u_{a}+d\right)$ is the value of $z$ at a point which is at distance $d$ from $u$. In practice, the pairs of data separated by distances within a certain lag are averaged. The spherical variogram, commonly
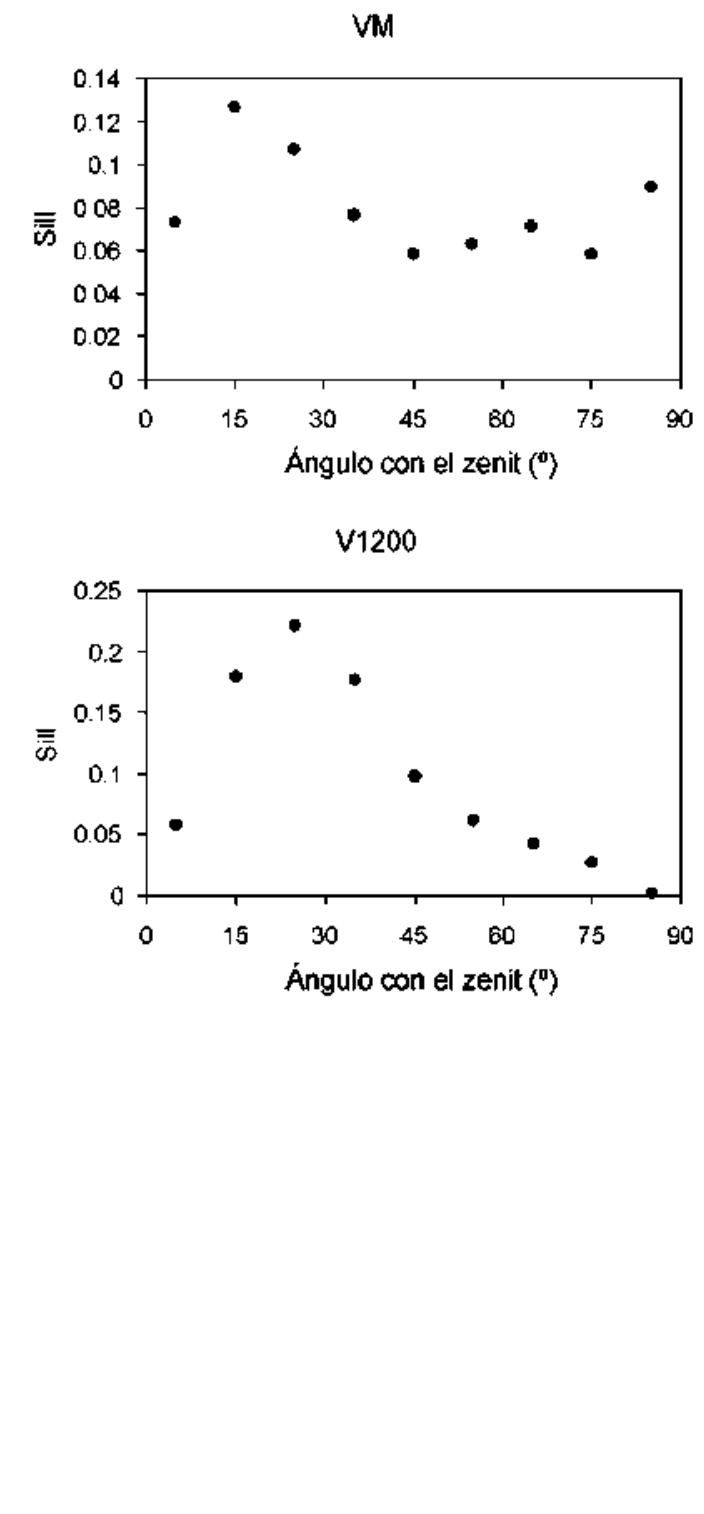

Fig. 4. Sill of the spherical variogram model fitted to the empirical variogram of the gap fraction obtained for each zenith direction for plots NM. VM, VR, V1200 and V1800. 
used to model environmental variables, provided a good fit for most of the experimental variograms obtained. The model was fitted to the experimental variogram using the minimum weighted squares method (Cressie, 1993):

$\sum_{j=1}^{k}\left(N(d(j))\left(\frac{\hat{\gamma}(d(j))}{\gamma(d(j) ; \theta)}-1\right)^{2}\right)$

Eq. (7) is minimized through an iterative process. $N(d(j))$ is the number of pairs of sample points between which the distance is within lag $j, k$ is the number of lags with more than 30 pairs of samples and $\theta$ refers to the variogram model parameters.

The software used for the calculus of the variogram was also developed using Microsoft VisualBasic 6.3 (Copyright ${ }^{\text {C) }} 1987$ 2001 Microsoft Corp.).

\section{Results}

\subsection{Angular variograms and cluster size derived from the hemispherical photographs}

The method involving spatial pattern analysis from hemispherical photographs, developed in the framework of this research, was used to determine the scale of the pattern of the stand from 10 photographs taken at each experimental plot.
The Fig. 3 shows the empirical angular variograms for the different zenith angles. as well as for the mean. along with the spherical model fitted for each zenith and for the mean angle in the experimental plots. It can be seen that the angular semivariance tends to be higher for the smaller zenith angles. decreasing as the zenith angle increases. This is due to the inclusion of a greater canopy extension in each sky sector for large zenith angles compared with small zenith angles, so that the gap fraction for the different sectors is more similar for large zenith angles. The semivariance was plotted against the zenith angle (in Fig. 4), displaying for all plots, except for plot $\mathrm{NM}$, a maximum, reached at a zenith direction of $15^{\circ}$ in the case of plot VM and $25^{\circ}$ for plots VR. V1200 and VI 800 . with a second maximum at $45^{\circ}$ for plot V1800. The gap fraction differentiation between clusters and gaps in the canopy must be maximum in the zenith direction corresponding to the maximum semivariance. The angular range of autocorrelation and the corresponding linear distance calculated through Eq. (3) with HMC given by Table 1 is shown in Table 2. In plot $\mathrm{NM}$, the short autocorrelation range $(3.06 \mathrm{~m})$ at the smallest zenith angle seems to indicate that the single crown constitutes the main aggregation level of the foliage. The scale of the pattern at the maximum semivariance zenith direction is $10.46 \mathrm{~m}$ for plot VM. $8.00 \mathrm{~m}$ for plot VR. $5.84 \mathrm{~m}$ for plot V1200 and $5.84 \mathrm{~m} / 10.38 \mathrm{~m}$ for plot V1800. Note that the linear range of autocorrelation was very similar for plots VM

Table 2

Sill of the spherical variogram model fitted to the empirical variogram of the gap fraction, angular range $\left(^{\circ}\right)$ and linear range (m) calculated using the Eq. (2) for the different zenith angles and experimental plots

\begin{tabular}{|c|c|c|c|c|c|c|c|c|c|c|c|}
\hline Plot & Zenith angle & $1^{\circ}$ & $15^{\circ}$ & $25^{\circ}$ & $35^{\circ}$ & $45^{\circ}$ & $55^{\circ}$ & $65^{\circ}$ & $75^{\circ}$ & $85^{\circ}$ & Mears \\
\hline & Sill & 0.25 & $0.2 \hat{3}$ & 0.20 & $0.1 \hat{3}$ & 0.10 & 0.06 & 0.11 & 0.11 & 0.05 & 0.13 \\
\hline \multirow[t]{3}{*}{ NM } & Range $\left({ }^{\circ}\right)$ & 176.38 & 73.61 & 60.30 & 17.50 & 41.21 & 65.34 & 226.23 & 237.55 & 121.64 & 89.81 \\
\hline & Range (m) & 3.06 & 5.62 & 8.21 & 3.73 & 12.33 & 27.01 & 69.11 & 114.62 & 349.68 & 24.74 \\
\hline & Sill & 0.07 & 0.13 & 0.11 & 0.08 & 0.06 & 0.06 & 0.07 & 0.06 & 0.00 & 0.07 \\
\hline \multirow[t]{3}{*}{$\mathrm{VM}$} & Range $\left({ }^{\circ}\right)$ & 97.30 & 191.47 & 95.58 & 100.50 & 58.58 & 48.13 & 64.00 & 49.09 & 80.97 & 79.34 \\
\hline & Range (m) & 2.58 & 10.46 & 13.55 & 21.11 & 19.19 & 22.84 & 44.57 & 60.80 & 291.04 & 25.04 \\
\hline & Sijl & 0.15 & 0.22 & 0.29 & 0.24 & 0.20 & 0.13 & 0.08 & 0.04 & 0.00 & 0.15 \\
\hline \multirow[t]{3}{*}{ VR } & Range $\left({ }^{\circ}\right)$ & 155.79 & 129.67 & 103.33 & 113.28 & 93.74 & 78.82 & 62.83 & 117.49 & 80.97 & 107.30 \\
\hline & Range (m) & 1.87 & 5.30 & 8.00 & 12.78 & 15.95 & 19.82 & 24.44 & 69.74 & 162.22 & 17.61 \\
\hline & Sill & 0.06 & 0.18 & 0.22 & 0.18 & 0.10 & 0.06 & 0.04 & 0.03 & 0.00 & 0.09 \\
\hline \multirow[t]{3}{*}{$V 1200$} & Range $\left({ }^{\circ}\right)$ & 174.50 & 125.46 & 87.06 & 70.59 & 59.19 & 75.12 & 135.77 & 139.36 & 80.97 & 93.36 \\
\hline & Range (m) & 1.59 & 4.33 & 5.84 & 7.35 & 8.98 & 15.83 & 36.12 & 63.63 & 134.91 & 13.23 \\
\hline & Sill & 0.15 & 0.18 & 0.25 & 0.22 & 0.25 & 0.23 & 0.19 & 0.09 & 0.04 & 0.18 \\
\hline \multirow[t]{2}{*}{ V1800 } & Range $\left({ }^{\circ}\right)$ & 210.20 & 114.24 & 137.51 & 109.97 & 101.16 & 139.05 & 151.41 & 89.66 & 69.52 & 124.13 \\
\hline & Range (m) & 1.14 & 3.02 & 5.84 & 7.71 & 10.38 & 17.98 & 27.93 & 35.36 & 87.59 & 11.87 \\
\hline
\end{tabular}

The lags where the semivariance reaches the maximum are shaded. 

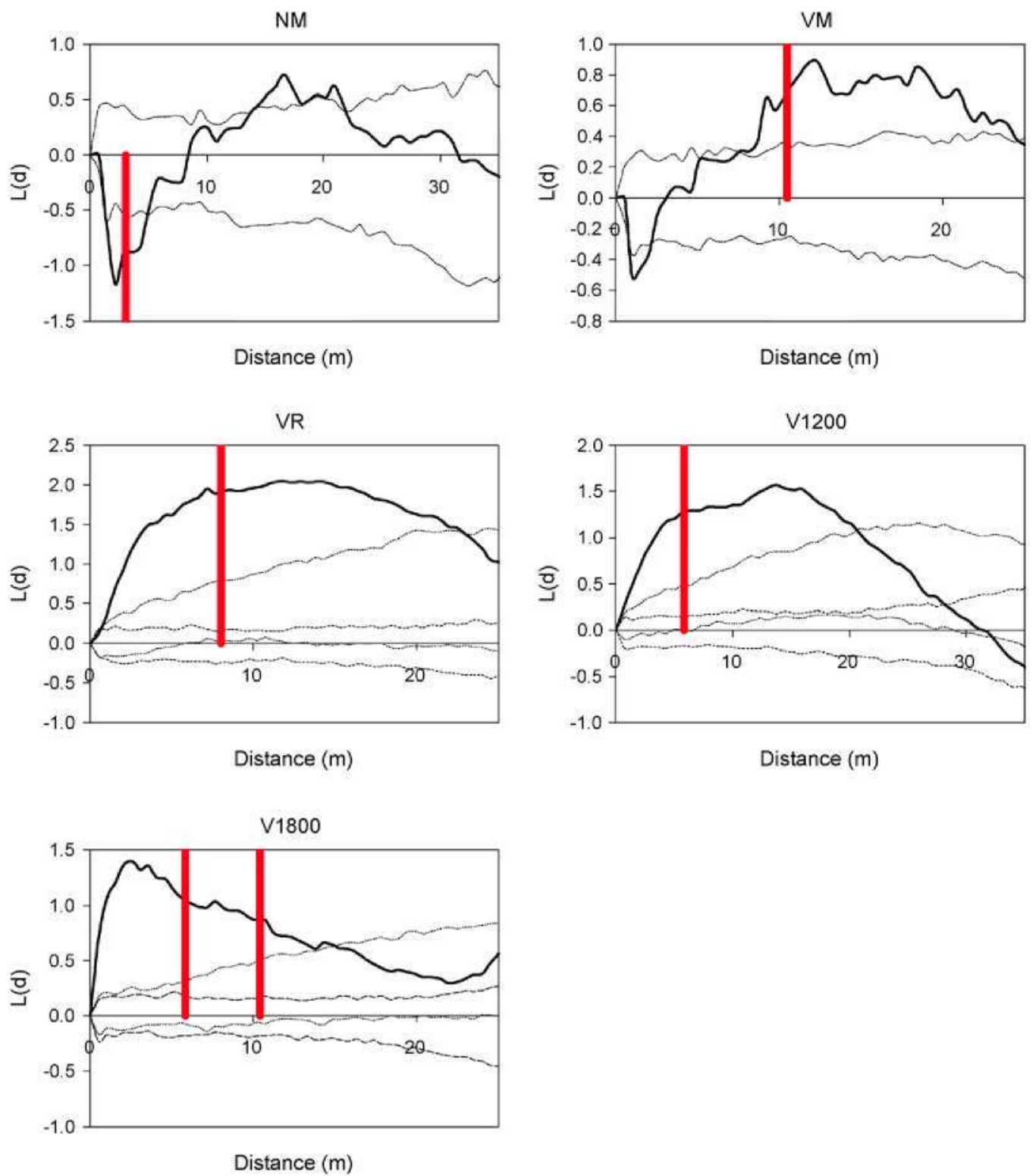

Fig. 5. Empirical $L(d)$ function (solid line) and the $95 \%$ quantiles bounds corresponding to CSR (discontinuous thin line) and MW (dotted thin line) null models for plots NM, VM, VR, V1200 and V1800. Vertical lines indicate the scale of the pattern obtained through hemispherical photograph.

and VR, which represent the mature stand at the beginning of the regeneration period and the established stand at the end of the regeneration period, respectively, and the maximum angular semivariance, where the scale of the pattern was identified, corresponded to the zenith angle of $15^{\circ}$ in plot VM, and $25^{\circ}$ in plot VR, due to the lower mean height of the young stand.

\subsection{Spatial pattern of stems derived from the mapped data}

The scale of the pattern derived from the hemispherical photograph data was compared with the results of the $L(d)$ function analysis. Fig. 5 shows the $L(d)$ function and the quantile bounds of the null models tested for each experimental plot. Plot NM shows a regular pattern at distances below $5 \mathrm{~m}$ approximately, indicating, as with the hemispherical photo- graph analysis, that the trees are over-dispersed. For this plot, the $L(d)$ function also shows small peaks above the upper $95 \%$ quantile of the CSR distribution at 17 and $22 \mathrm{~m}$, but is not significantly different from the CSR at larger distances. Plot VM displays a regular pattern for distances shorter than $2.5 \mathrm{~m}$, but from 6 to $25 \mathrm{~m}$ it shows cluster pattern. In the rest of the plots, where the mean density apparently shows a large-scale variation throughout the plot, the MW null model was used aside from the CSR, to test random distribution at small scale within a large-scale pattern. In plots VR and V1200, MW reveals clustering at distances shorter than $22 \mathrm{~m}$ approximately, whereas plot V1800 displays a cluster pattern below distances of around $14 \mathrm{~m}$, although the empirical $L(d)$ function shows an increasing trend at the end of the analysed range. The linear range of autocorrelation derived from the hemispherical photographs falls within the range of the regular pattern for 

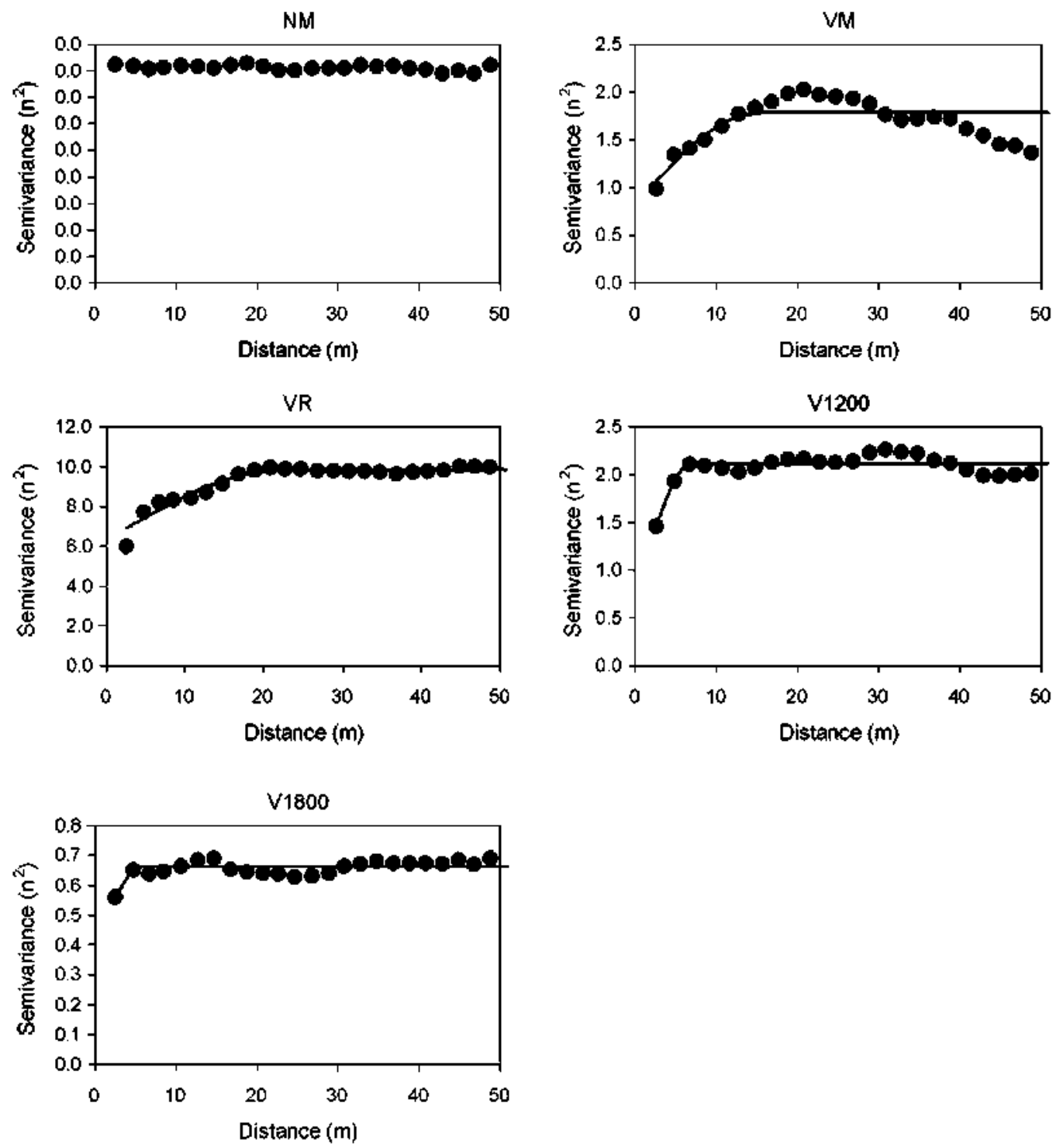

Fig. 6. Empirical semivariogram and spherical semivariogram model fitted with the number of all the trees of height $>1.30 \mathrm{~m}$ by quadrat for plots $\mathrm{NM}$ (only empirical semivariogram), VM. VR, V1200 and V 1800 .

plot NM and the range of the cluster pattern for plots VM. VR, V1200 and V1800 (Fig. 5).

\subsection{Spatial pattem derived from the quadrat counts}

The empirical semivariograms of the number of trees in the $2 \mathrm{~m} \times 2 \mathrm{~m}$ quadrats for trees higher than $1.30 \mathrm{~m}$ in the different plots are shown in the Fig. 6 . In the same figure, the spherical semivariogram model fitted has been plotted. The range of autocorrelation corresponds to the average size of clusters and gaps. Plot NM shows no spatial autocorrelation, indicating that the variable was homogenously distributed. For plots VM. VR, V1200 and V1800, the empirical semivariogram indicates the presence of spatial autocorrelation. The parameters for the spherical semivariogram fitted are shown in Table 3 . The range of autocorrelation is very similar for plots VM, VI200 and $\mathrm{V} 1800$ with the linear range calculated from the hemispherical photographs in Table 2 and falls within the range of the significant cluster pattern in the $L(d)$ function analysis. For plot VR, the range of autocorrelation is larger than the linear range from the hemispherical photographs, being at the larger scales of the significant cluster pattern in the $L(d)$ function analysis. However, the variogram for plot VR seems to show in Fig. 6 two steps. with ranges around 8 and $22 \mathrm{~m}$, respectively. This may indicate the existence of different patterns due to the mixture of young trees and mother trees in the plot. Similarly, the large

Table 3

Value of the spherical semivariogram parameters fitted through Weighted Least Squares

\begin{tabular}{lllc}
\hline Plot & Nugget $\left(\mathrm{n}^{2}\right)$ & Sill $\left(\mathrm{n}^{2}\right)$ & Range $(\mathrm{m})$ \\
\hline NM & - & - & - \\
VM & 0.83 & 1.78 & 15.24 \\
VR & 6.29 & 9.83 & 22.41 \\
V1200 & 0.72 & 2.12 & 6.91 \\
V1800 & 0.39 & 0.66 & 5.72 \\
\hline
\end{tabular}


range of clustering given by the $L(d)$ function for plot VR (Fig. $5 \mathrm{c}$ ), indicates a great variability in patch sizes.

\section{Discussion}

In this paper, a method is proposed for assessing the spatial pattern of forest stands from hemispherical photographs. This method allows the scale of the stand pattern to be determined from hemispherical photographs as long as an estimation of the average height of the canopy layer is available. As can be seen in Fig. 3, the gap fraction by sky sectors estimated from the photograph, presents spatial autocorrelation. This autocorrelation is due to the cluster structure of foliage in the canopy. which appears at three levels: (i) shoots and foliage elements within the crown. (ii) crowns and (iii) aggregates of crowns (Weiss et al., 2004). The clustering within the crown may only result in spatial autocorrelation of the gap fraction at very small zenith angles. because sky sectors at larger zenith angles comprise an extension beyond that of a single crown at canopy height. The crowns might be regularly distributed in the canopy layer or they might form gaps where the visible sky in the photograph increases. If the crowns are regularly distributed, as in plot NM, the maximum semivariance will appear near to the vertical zenith direction where the photograph may display "crown" or "no crown". The pattern of the aggregates formed by several crowns may be detected at intermediate zenith angles, whereas at large zenith angles. the longer path of the sunbeam through the canopy leads to a reduction in the transmittance (Nilson. 1971) and, therefore. a continuity in the sky sectors between crown groups at different distances that reduces the clustering effect on the gap fraction (Kucharik et al.. 1999) and increases the autocorrelation range. The pattern of groups and gaps will be most evident in the zenith direction where the angular semivariance. defined by Eq. (1), reaches a maximum, although the effect of the slope. which leads to an increase in semivariance values (as for plot NM, in Fig. 4a, which has the steepest slope), must be taken into account where the direction of the sunbeam is close to the horizon. Several strictures originating from various processes may also generate aggregation at different scales, as for plot V1800, where a small scale aggregated structure together with the large gaps existing in this plot lead to the presence of two peaks in the angular semivariogram. In fact, when the gap fraction of all the zenith angles is averaged, the autocorrelation range will include the variability from various sources of clustering at different scales. Therefore. the scale of the pattern is determined using only the zenith direction where the angular semivariance reaches a peak.

Although one might expect the spatial pattern to be the same using any assessment method, there is a notable difference between the pattern obtained using the hemispherical photograph method and that obtained using second moment analysis. as the former averages the spatial autocorrelation of both clusters and gaps, whereas the second moment analysis reflects the pattern of the clusters. In this sense, the scale of the pattern assessed through the range of spatial autocorrelation of the number of trees per quadrat should be closer to the scale derived from the hemispherical photographs. Indeed, for plots NM, VI200 and V1800, the scale of the pattern obtained from the hemispherical photographs bore greater resemblance to the autocorrelation range for the quadrats than to the distance at which the $L(d)$ function peaks. However, in the case of plots VM and VR, the scale of the pattern assessed through the photographs was closer to the distance at which the $L(d)$ function reaches a maximum. with respect the CSR and the MW null models respectively (Fig. 5), than to the autocorrelation range for the quadrats This may be due to the high fraction of small size trees in those plots, as these determine the spatial pattern in the $2 \mathrm{~m} \times 2 \mathrm{~m}$ grid but are not taken into account when calculating the $L(d)$ function and have little effect on the gap distribution in the photograph.

The spatial pattern assessment technique proposed in this paper allows the spatial pattern of the stand to be characterized without the need to map the trees. thus avoiding this costly and time consuming task and allowing spatial pattern assessment be easily implemented in forest inventories. The pattern is characterized at canopy level and is closely related to the light environment within the stand as well as to the state of development. This paper expounds how the scale of the pattern derived from hemispherical photograph data. as well as the zenith angles where the sill of the angular variogram is maximum. provide valuable information as regards the effect on stand structure of silviculture. environmental conditions or ecological processes such as regeneration or species interaction. The results of this study highlight the differences in the spatial pattern during the regeneration process in the Valsain and Navafría forests. In Navafría, where the thinning regime is more intensive and the regeneration fellings are carried out over a shorter period, the pattern of the mother trees is quite regular (plot N5), leading to very homogeneous conditions throughout the regenerating stand, and consequently, a more homogeneous establishment of the recruitment. In Valsain, the pattern of the remaining old crop during the regeneration process (plot VM) is clustered, leading to an irregular distribution of the young stand (plot VR). This irregular structure during the regeneration process seems to facilitate the nanıral regeneration of Scots pine in the Valsain forest (Montes and Cañellas, 2007). The present study also reveals a clustered spatial pattern in plot V1800 located at the altitudinal tree line, where site and climatic conditions are limiting factors for tree species. at smaller scales than in the other plots. This clustered pattern at the tree line has been reported in other studies (Camarero et al..2000) and may be due to factors such as the greater incidence of disturbances caused by wind or snow or the spatial distribution of micro-sites suitable for regeneration establishment (Jones and del Moral. 2005). The 'smothering' of extreme conditions within the cluster may also be important in this respect and may be reflected in the spatial association between seedlings and mature trees identified in plot V1800 (Barbeito et al., 2006), similarly to the 'wave regeneration', where the windward neighbours protect and aid the development of tree species (Sato and Iwasa, 1993). The small scale mosaic formed by the Scots pine and Pyrenean oak patches in plot V1200, where there is a gradual progression from pine dominance in the upper part of the plot to oak dominance in the lower part. results in a cluster pattern at scales around $6-10 \mathrm{~m}$. and indicates that both species coexist in relative equilibrium at 
this site. Patch dynamics may lead to the coexistence of competing species when there is a trade-off between competition and dispersal (Skellam. 1951; Pacala and Levin, 1997: Amarasekare and Nisbet, 2001; Murrell and Law. 2003).

\section{Conclusions}

The spatial pattern assessment technique proposed in this paper allows the spatial pattern of the forest canopy to be characterized from hemispherical photographs and is easily implemented in forest inventories. This method provides useful information about stand structure and the underlying management and ecological processes. Although this paper centres on detecting the scale of the pattern, future work may be aimed at identifying different spatial structures originating from the presence of different ecological processes or species with different ecological requirements in complex stands as well as to determine how the spatial structure might be related to the availability of habitats which are suitable for threaten species. Processes taking place at landscape level may be analysed through the large-scale variation of the microscale stand pattern using georeferenced data sets. Moreover. the spatial pattern assessment technique developed in this study may be adapted to obtain a model suitable for analysing the effect of clumping on the gap fraction and improve the accuracy of LAI estimation from indirect optical methods.

\section{Acknowledgments}

The authors wish to thank Angel Bachiller and Estrella Viscasillas for their help in the fieldwork and Adam Collins for the language revision. This study has been funded by projects AGL2004-07094.CO2.01/FOR and AGL2004-01941/FOR of the Spanish Ministry of Education and Science.

\section{References}

Aldrich. P.R.. Parker. G.R.. Ward, J.S.. Michler, C.H.. 2003. Spatial dispersion of trees in an old-growth temperate hardwood forest over 60 years of succession. Forest Ecol. Manage. 180, 475-491.

Amarasekare, P., Nisbet, R.M., 2001. Spatial beterogeneity, source-sink dynamics. and the local coexistence of competing species. Am. Nat. $158,572-584$

Barbejto, I., Montes, F., Pardos, M., Cañellas, I., 2006. Effect of the previous stand structure on regeneration dynamics of Pinus syivestris $\mathbf{L}$. under different environmental conditions in the Central Mountain Range (Spain). In: Proceedings of the Intemational IUFRO Conference Nearest Neighbors Workshop, University of Minnesota.

Camarero, J.J., Gutiérrez, E., Fortin, M.J., 2000. Spatial pattern of subalpine forest-alpine grassland ecotones in the Spanish Central Pyrenees. Forest Ecol. Manage. 134, 1-6.

Chen, J.M., Ciblar, J., 1995. Quantifying the effect of canopy architecture on optical measurements of leaf area index using two gap size analysis methods. IEEE Trans. Geosci. Remote Sensing 33, 777-787.

Cressie. N.A.C.. 1993. Statistics for Spatial Data. Wiley, New York.

Dale, M.R.T., 1999. Spatial Pattern Analysis in Plant Ecology. Cambridge University Press, Cambridge.

Dale, M.R.T., Dixon. P.. Fortin, M.J.. Legendre, P., Myers. D.E.. 2002. Conceptual and mathematical relationships among methods for spatial analysis. Ecography 25, 558-577.
DeLagrange, S., Messier, C.. Lechowicz, M.J.. Dizengremel, P., 2004. Physiological, morphological and allocational plasticity in understory deciduous trees, importance of plant size and light availability. Tree Physiol. 24. $775-784$.

Denslow. J.S., Guzman. S.. 2000. Variation in stand structure, light and seedling abundance across a tropical moist forest chronosequence, Panama. J. Veg. Sci. 11, 201-212.

Druckenbrod, D.L., Shugart, H.H., Davies, I., 2005. Spatial pattern and process in forest stands within the Virginia piedmont. J. Veg. Sci. 16, $37-48$.

Fassnacht, K.S., Gower, S.T., Norman, J.M., McMurtrie, R.E., 1994. A comparison of optical and direct methods for estimating foliage surface area index in forests. Agric. Forest Meteorol. 71, 183-207.

Franklin. J.F.. Spies, T.A., Pelt. R.V.. Carey, A.B.. Thornburgh. D.A., Berg, D.R., Lindenmayer, D.B., Harmon, M.E., Keeton, W.S., Shaw, D.C., Bible, K. Chen, J., 2002. Disturbances and structural development of natural forest ecosystems with silvicultural implications, using Douglas-fir forests as an example. Forest Ecol. Manage. 155. 399-423.

Goreand. F., Pélissier, R., 1999. On explicit formulas of edge correction for Ripley's $K$-function. J. Veg. Sci. 10, 433-438.

Hanewinkel, M.. 2004. Spatial patterns in mixed coniferous even-aged. unevenaged and conversion stands. Eur. J. Forest Res. 123, 139-155.

Hunter, M.L., 1990. Wildlife, Forests, and Forestry, Principles of Managing Forests for Biological Diversity. Prentice-Hall, Englewood Cliffs, N.J.

Jones, C.C., del Moral. R.. 2005. Effects of microsite conditions on seedling establishment on the foreland of Coleman Glacier. Washington. J. Veg. Sci. $16,293-300$.

Keitt, T.H., Bjørnstad, O.N., Dixon, P.M., Citron-Pousty, S., 2002. Accounting for spatial pattern when modelling organism-environment interaction. Ecography 25, 616-625.

Konkoulas, S., Blackburn, G.A., 2005. Spatial relationships between tree species and gap characteristics in broad-leaved deciduous woodland. $\mathbf{J}$. Veg. Sci. 16, 587-596.

Kucharik. C.J.. Norman, J.M.. Gower, S.T.. 1999. Characterization of radiation regimes in non random forest canopies: theory, measurements, and a simplified modelling approach. Tree Physiol. 19, 695-706.

Kuuluvainen. T.. Penttinen, A., Leinonen, L.. Nygren. M.. 1996. Statistical opportunities for comparing stand structural heterogeneity in managed and primeval forests, an example from boreal Spruce forest in Southern Finland. Silva Fennica 30, 315-328.

Legendre. P.. Legendre. L., 1998. Numerical Ecology. second ed. (English) Elsevier Publishers. Amsterdam.

Legendre, P., Dale, M.R.T., Fortin, M.J., Casgrain, P., Gurevitch, J., 2004. Effects of spatial structures on the results of tield experiments. Ecology 85 . 3202-3214.

Maestre. F.T.. Escudero. A., Martínez, I.. Guertero. C.. Rubio, A., 2005. Does spatial pattern matter to ecosystem functioning? Insights from biological soil crusts. Funct. Ecol. 19, 566-573.

Magurran, A.E., 1988. Ecological Diversity and its Measurement. Princeton University Press, Princeton, NJ.

Moent, M. 1993. Characterizing spatial patterns of trees using stem-mapped data. Forest Sci. 39, 756-775.

Montes, F., Caniellas, I., 2007. The spatial relationship between the remaining trees from the previous crop and the establishment and development of saplings in Pintus swlvestris L. stands in Spain. Appl, Veg. Sci. 10, 151-160.

Montes, F., Cañellas, I., del Rio, M., Calama, R., Montero, G., 2004. The effects of thinning on the structural diversity of coppice forests. Ann. Forest Sci. 61 , $771-779$.

Montes, F.. Sánchez, M., del Río, M., Cañellas, I.. 2005. Using historic management records to characterize the effects of management on the structural diversity of forests. Forest Ecol. Manage. 207, 279-293.

Montgomery. R.A.. Chazdon. R.L., 2001. Forest structure, canopy architecture, and light transmittance in old-growth and second-growth tropical rain forests. Ecology 82, 2707-2718.

Montgomery, R.A., Chazdon, R.L., 2002. Light gradient partitioning by tropical tree seedlings in the absence of canopy gaps. Oecologia 131, 165-174.

Murrell, D.J., Law, R.. 2003. Heteromyopia and the spatial coexistence of similar competitors. Ecol. Lett. 6, 48-59. 
Neumann, H.H., Hartog. G.d.. Shaw, R.H., 1989. Leaf area measurements based on hemispheric photographs and leaf litter collection in a deciduous forest during antumn leaf fall. Agric. Forest Meteorol. 45, 325-345.

Nenman, M. Starlinger, F., 2001. The signiticance of different indices for stand structure and diversity in forest. Forest Ecol. Manage. 145. 91-106.

Nilson, T., 1971. A theoretical analysis of the frequency of gaps in plant stands. Agric. Meteorol. 8, 25-38.

Nicotra, A.B., Chazdon, R.L., Iriarte, S.V.B., 1999. Spatial beterogenejty of light and woody seedling regeneration in tropical wet forests. Ecology 80, 1908-1926.

Pacala, S.W., Levin, S.A., 1997. Biologically generated spatial pattern and the coexistence of competing species. In: Tilman, D., Karejva, P. (Eds.), Spatial Ecology. The Role of Space in Population Dynamics and Interspecitic Interactions. Princeton University Press. Princeton, NJ. pp. 204-232.

Pardos, M., Montes, F., Aranda, I., Cantellas, I., 2007. Influence of environmental conditions on Scots pine (Pinus svivestris L.) germinant survival and diversity in central Spain. Eur. J. Forest Res. 126, 37-47.
Penry. J.N., Liebhold, A.M.. Rosenherg, M.S., Dungan. J.L., Miriti, M.. Jakomulska, A., Citron-Pousty, S., 2002. Illustrations and guidelines for selecting statistical methods for quantifying spatial pattern in ecological data. Ecography 25, 578-600.

Ripley. B.D., 1977. Modelling spatial patterns (with discussion). J. R. Stat. Soc. 39. $172-212$.

Ripley, B.D., 1981. Spatial Statistics. John Wiley. Sons, New York.

Satō, K., Iwasa, Y., 1993. Modelling of wave regeneration in subalpine Abies forests. population dynamics with spatial structure. Ecology 75, 1538-1550.

Skellam, J.G., 1951. Random dispersal in theoretical populations. Biometrika 38, 196-218.

Watt, A.S., 1947. Pattern and process in the plant comunity. J. Ecol. 35, 1-22.

Weiss, M.. Baret, F.. Smith, G.j.. Jonckheere. I.. Coppin, P., 2004. Review of methods for in situ leaf area index determination. Part II. Estimation of LAI. errors and sampling. Agric. Forest Meteorol. 121, 37-53.

Wiegand, T., Moloney, K.A., 2004. Rings, circles, and null-models for point pattem analysis in ecology. Oikos 104, 209-229. 